\title{
High-Temperature Resistant Polyborosilazanes with Tailored Structures
}

\author{
Bijie Wang 1,2 ${ }^{\mathbb{D}}$, Ke Chen ${ }^{2,3}$, Tianhao Li ${ }^{2,3}$, Xun Sun ${ }^{4}$, Ming Liu ${ }^{2,4}$, Lingwei Yang ${ }^{5}$, Xiao (Matthew) Hu ${ }^{2,6}$, \\ Jian $\mathrm{Xu}^{2,3}$, Liu He ${ }^{2,3}$, Qing Huang ${ }^{2,3}$, Linbin Jiang ${ }^{1, *}$ and Yujie Song ${ }^{2,3, *}$
}

1 Guangxi Key Laboratory of Petrochemical Resource Processing and Process Intensification Technology, School of Chemistry and Chemical Engineering, Guangxi University, Nanning 530004, China; wangbijie@nimte.ac.cn

2 Engineering Laboratory of Advanced Energy Materials, Ningbo Institute of Materials Technology \& Engineering, Chinese Academy of Sciences, Ningbo 315201, China; chenke@nimte.ac.cn (K.C.); litianhao2057@nimte.ac.cn (T.L.); liuming0117@hit.edu.cn (M.L.); ashxu@ntu.edu.sg (X.H.); xujian@nimte.ac.cn (J.X.); heliu@nimte.ac.cn (L.H.); huangqing@nimte.ac.cn (Q.H.)

3 Qianwan Institute of CNiTECH, Ningbo 315336, China

4 Harbin Institute of Technology, 92 West Dazhi Street, Nan Gang District, Harbin 150001, China; sxun201@hit.edu.cn

5 Hypervelocity Aerodynamics Institute, China Aerodynamics Research and Development Center, Mianyang 621000, China; lingwei.yang@cardc.cn

6 School of Materials Science and Engineering, Nanyang Technological University, Block N4.1, Nanyang Avenue, Singapore 639798, Singapore

* Correspondence: jlb39203@gxu.edu.cn (L.J.); songyujie@nimte.ac.cn (Y.S.)

Citation: Wang, B.; Chen, K.; Li, T.; Sun, X.; Liu, M.; Yang, L.; Hu, X.; Xu, J.; He, L.; Huang, Q.; et al. High-Temperature Resistant Polyborosilazanes with Tailored Structures. Polymers 2021, 13, 467. https://doi.org/10.3390/polym 13030467

Academic Editors: Begoña Ferrari and Zoilo González

Received: 12 January 2021

Accepted: 28 January 2021

Published: 1 February 2021

Publisher's Note: MDPI stays neutral with regard to jurisdictional claims in published maps and institutional affiliations.

Copyright: (c) 2021 by the authors. Licensee MDPI, Basel, Switzerland. This article is an open access article distributed under the terms and conditions of the Creative Commons Attribution (CC BY) license (https:/ / creativecommons.org/licenses/by/ $4.0 /)$.

\begin{abstract}
Boron-containing organosilicon polymers are widely used under harsh environments as preceramic polymers for advanced ceramics fabrication. However, harmful chemicals released during synthesis and the complex synthesis routes have limited their applications. To solve the problems, a two-component route was adopted to synthesize cross-linked boron-containing silicone polymer (CPBCS) via a solventless process. The boron content and CPBCSs' polymeric structures could be readily tuned through controlling the ratio of multifunctional boron hybrid silazane monomers (BSZ12) and poly[imino(methylsilylene)]. The CPBCSs showed high thermal stability and good mechanical properties. The CPBCS with $\mathrm{Si}-\mathrm{H} / \mathrm{C}=\mathrm{C}$ ratio of $10: 1$ showed $75 \mathrm{wt} \%$ char yields at $1000^{\circ} \mathrm{C}$ in argon, and the heat release capacity (HRC) and total heat release (THR) are determined to be $37.9 \mathrm{~J} / \mathrm{g} \mathrm{K}$ and $6.2 \mathrm{KJ} / \mathrm{g}$, demonstrating high thermal stability and flame retardancy. The reduced modulus and hardness of CPBCS are $0.30 \mathrm{GPa}$ and $2.32 \mathrm{GPa}$, respectively. The novel polysilazanes can be potentially used under harsh environments, such as high temperatures or fire hazards.
\end{abstract}

Keywords: polyborosilazane; boron-containing polymer; high temperature resistant

\section{Introduction}

Organic-inorganic hybrid polymers have attracted much attention in recent years since they possess high-temperature resistance, anti-oxidation properties, and high mechanical strength from the inorganic segments, and processibility as well as flexibility from the organic segments [1-6]. The bottom-up approach provides enormous benefits from molecular design to tailored polymeric structures [7]. The possibility of structural design at the molecular level offers great potential in the fabrication of novel materials with desired mechanical and functional properties [8].

Organic-inorganic hybrid polymers, such as polysiloxanes, are widely used as flameretardant materials, and molecular structure design was adopted to further enhance the flame retardancy, eliminate the use of halogen, and reduce potential environmental impacts [9-12]. Xie et al. synthesized a new phosphorus-containing ternary copolymer flame-retardant material with octa-vinyl polyhedral oligomeric silsesquioxane and poly 
(methyl methacrylate). The material exhibits good optical properties, impact resistance, and mechanical strength [13]. Compared with polysiloxanes, polysilazanes, which are mainly composed of $\mathrm{Si}, \mathrm{N}$, and $\mathrm{C}$ elements, have better mechanical properties and higher thermal stability $[14,15]$. The nitrogen atoms of polysilazanes could provide potential binding sites for certain chemical species [16], and the extra N-H bonds could react with $\mathrm{Si}-\mathrm{H}$ or Si-vinyl bonds, allowing the further molecular design for targeted mechanical and functional properties [17]. However, polysilazanes were mostly used as the precursor of $\mathrm{SiCN}$ ceramics $[18,19]$. The one-step preparation process of polysilazanes is complicated, high cost, and it is difficult to obtain polysilazanes with high molecular weight or controlled molecular structure. The hydrolytic instability of the Si-N bonds is a bottleneck that restricts the potential applications $[20,21]$.

Boron compounds are one class of commonly used flame retardant additives [22-26]. Boron can increase the crosslinking density, reduce the degree of disordered structure, and improve the heat resistance, corrosion resistance, and ablation resistance of the materials [27-30]. The incorporation of boron atoms into polysilazanes could lower their sensitivity to moisture due to reduced N-H concentration, and the synergistic effect of silicon and boron compounds provides good thermal-oxidative stability, contributing to a higher char yield, a better graphitization degree after sintering, and good flame retardancy property [8]. Yajima et al. synthesized poly(borondiphenylsiloxane) by reacting boric acid with diphenyldichlorosilane or diphenylsilane diol, and they investigated the thermal decomposition process [31]. Sundar and Keller synthesized a linear boron-silicon-diacetylene copolymer with a residual content of more than $50 \%$ at $1000{ }^{\circ} \mathrm{C}$ in air [32]. Zhou et al. synthesized linear borosilicate hybrid polymers containing $\mathrm{C} \equiv \mathrm{C}$ units that demonstrated excellent thermal and oxidation stability [33].

However, the traditional aminolysis method used to synthesize polyborosilazanes uses environmentally hazardous chemicals (ammonia, methylamine, chlorosilazane, and pinacol borane), and the generated by-products must be specially treated. [34-36]. Thus, it is important to find an environmentally friendly and efficient method to synthesize polyborosilazanes.

Here, in this article, we synthesized borosilazane crosslinker via hydroboration reaction and used it to crosslink polysilazane through solventless hydrosilylation reaction without the generation of any by-products. The polymer structures and boron content could be readily tuned through adjusting the ratio of monomers used. The influence of the polymer structures on the mechanical properties and thermal properties is discussed. The design and synthesis of polyborosilazanes with tailored structures and targeted properties provide new insight into the design of new types of high-performance polymers.

\section{Materials and Methods}

\subsection{Materials}

Tetrahydrofuran (THF), borane-methyl sulfide complex (BDMS, 2.0 M solution in THF), 1,1,3,3-tetramethyl-1,3-divinyldisilazane (TMDS), and Karstedt Catalyst Solution (Pt: $\approx 2 \%$ Xylene solution) were purchased from Aladdin Reagent Co., Ltd. (Shanghai, China). Poly[imino(methylsilylene)] (PNSZ) was purchased from Guangzhou Winhigh Chemical \& Technology Co. Ltd. (Guangzhou, China). All chemicals were used as received.

\subsection{Preparation of BSZ12 Monomer}

TMDS was dissolved in anhydrous THF under constant stirring in an ice-water bath for $20 \mathrm{~min}$. BDMS was added to the TMDS solution drop by drop. The resultant solution was stirred overnight at room temperature under the protection of Argon. A transparent liquid was obtained after the solvent removal.

\subsection{Preparation of Cross-Linked Boron-Containing Silicone Polymers (CPBCSs)}

CPBCSs were prepared by mixing BSZ12, PNSZ, and Karstedt Catalyst solution (the concentration of $\mathrm{Pt}$ was $412 \mathrm{ppm}$ ) with different $\mathrm{Si}-\mathrm{H} / \mathrm{C}=\mathrm{C}$ ratios. The samples were cured 
at $100{ }^{\circ} \mathrm{C}$ in air and further treated at $300{ }^{\circ} \mathrm{C}$ for $2 \mathrm{~h}$ under argon flow. The ratios of BSZ12 and PNSZ are listed in Table 1.

Table 1. Ratios of multifunctional boron hybrid silazane monomers (BSZ12) and poly[imino(methylsilylene)] (PNSZ) for synthesizing cross-linked boron-containing silicone polymers (CPBCSs).

\begin{tabular}{cccc}
\hline Sample & BSZ12 (g) & PNSZ $(\mathbf{g})$ & Molar Ratio $(\mathrm{Si}-\mathrm{H} / \mathrm{C}=\mathrm{C})$ \\
\hline CPBCS10-1 & 1.2962 & 4.000 & $10-1$ \\
CPBCS5-1 & 2.5924 & 4.000 & $5-1$ \\
CPBCS3-1 & 3.2192 & 3.000 & $3-1$ \\
\hline
\end{tabular}

\subsection{Characterization}

${ }^{1} \mathrm{H}-\mathrm{NMR}$ and ${ }^{11} \mathrm{~B}-\mathrm{NMR}$ spectra were performed inside a Bruker AVANCE III UltraShield (Bruker, Fällanden, Switzerland) spectrometer at 400 and $128 \mathrm{MHz}$, respectively. Tetramethylsilane (TMS) was used as the reference material as an internal standard in $\mathrm{CDCl}_{3}$ solutions at $25^{\circ} \mathrm{C}$.

Thermal analysis was performed inside a simultaneous thermal analyzer (STA; NETZSCH STA449F3, Berlin, Germany) at a heating rate of $10^{\circ} \mathrm{C} / \mathrm{min}$ under an argon and air atmosphere.

The Fourier transform infrared (FTIR) spectra were performed inside a Nicolet Avatar 360 (Thermo Fisher Scientific, Inc., Waltham, MA, USA) spectrometer using KBr disks. Spectra were recorded from 400 to $4000 \mathrm{~cm}^{-1}$ with 32 scans. The Ultraviolet-visible (UVVis) spectra were performed inside a Perkin-Elmer Lambda 950 (PerkinElmer, Waltham, MA, USA) spectrophotometer. Spectra were recorded from 200 to $800 \mathrm{~nm}$.

The oxygen content and nitrogen content were determined by a LECO ON836 (LECO, Mönchengladbach, Germany), the carbon content was determined by LECO CS600, the hydrogen content was determined by an organic element analyzer (Elementar, Langenselbold, Germany), and the boron content was determined by an ICP-OES (SPECTRO ARCOS II, Kleve, Germany). The silicon content was calculated by subtracting the mass percentage of other elements.

The nanoindentation test was performed inside a NanoTest Vantage system (MML, England) equipped with a diamond Berkovich indenter. The indentation load was applied at a constant strain rate (0.05), considering the strain rate-dependent behavior of polysilazanes polymers. The peak load was set at $5 \mathrm{mN}$ and maintained for $5 \mathrm{~s}$. A fixed unloading time ( $5 \mathrm{~s})$ was used for all experiments. Based on the obtained indentation force-displacement curves, the reduced modulus $\left(E_{r}\right)$ and hardness $(H)$ were calculated based on the Oliver-Pharr method [37]. The Young's modulus $(E)$ can be finally correlated with $E_{r}$ by:

$$
\frac{1}{E_{r}}=\frac{\left(1-v^{2}\right)}{E}+\frac{1-v_{i}^{2}}{E_{i}}
$$

here, $E_{i}$ and $v_{i}$ are the Young's modulus and Poisson's ratio of a diamond indenter (1147 GPa and 0.07$). v$ is the Poisson's ratio of polysilazanes polymers, and an average value of 0.25 was used for all calculations.

Water contact angle analyses were performed inside a Dataphysics OCA25 using shape image analysis with $1 \mu \mathrm{L}$ of water droplets, and the contact angle was calculated as an average of at least five samples. The surface morphologies were performed inside a Bruker Dimension icon with ScanAsyst (Bruker, Santa Barbara, CA, USA) and conducted in contact mode. The scanning sizes were $10 \mathrm{~nm} \times 10 \mathrm{~nm}$, and the lines are 512 .

The combustibility was performed inside a pyrolysis combustion flow calorimetry (PCFC) by applying a micro-scale combustion calorimetry (MCC, Govmark MCC-2, Rochester, NY, USA) from Fire Testing Technology (FTT). First, $5 \pm 1 \mathrm{mg}$ of powder sample was heated under nitrogen flow up to $750^{\circ} \mathrm{C}$ with a heating rate of $1 \mathrm{~K} / \mathrm{s}$. The heat release capacity (sumHRC) in J/g K was calculated by a ratio of the sum of peak HRR (pHRR-the maximum heat release rate) to the average heating rate in $\mathrm{K} / \mathrm{s}$. The total heat release (THR) 
in $\mathrm{kJ} / \mathrm{g}$ was equal to the area below the curve of the heat release rate as a function of the pyrolysis temperature.

\section{Results}

\subsection{Synthesis of BSZ12 Monomer and CPBCSs}

BSZ12 and CPBCS were synthesized according to Figure 1. The structure of hyperbranched CPBCSs could be adjusted through changing the molar ratio of $\mathrm{Si}-\mathrm{H} / \mathrm{C}=\mathrm{C}$. Figure 2a shows the FTIR spectra of TMDS and BSZ12. The new peaks that appeared at $1092 \mathrm{~cm}^{-1}$ (C-B stretching) and $2875 \mathrm{~cm}^{-1}\left(-\mathrm{CH}_{2}\right.$ - stretching) demonstrated that hydroboration occurred. However, the peak at $1338 \mathrm{~cm}^{-1}$ also indicated that the dehydrogenation reaction occurred between $\mathrm{N}-\mathrm{H}$ and $\mathrm{B}-\mathrm{H}$, forming a B-N bond in BDMS. Hydroboration and dehydrogenation occurred simultaneously with the presence of $\mathrm{N}-\mathrm{H}$ [38], and the resulting product (BSZ12) was a mixture of products from the two reactions (Figure 2b). This could be further verified by the ${ }^{1} \mathrm{H}$ NMR spectrum (Figure 2c). The peaks range of 0.12-0.24 ppm (I) in ${ }^{1} \mathrm{H}$ NMR spectrum is assigned to $\mathrm{Si}_{-} \mathrm{CH}_{3}$. The peaks at 0.50 (II) and $0.93 \mathrm{ppm}$ (III) are assigned to $\mathrm{Si}-\mathrm{CH}_{2}-\mathrm{CH}_{2}-$ and methine in $\mathrm{Si}-\mathrm{CH}\left(\mathrm{CH}_{3}\right)$ - groups. The peak at $1.24 \mathrm{ppm}(\mathrm{IV})$ is assigned to $-\mathrm{CH}_{3}$ in $\left.\mathrm{B}-\mathrm{CH}\left(\mathrm{CH}_{3}\right)-\right)$. The peaks at 3.71-4.12 $\mathrm{ppm}(\mathrm{V})$ are assigned to the protons of the ethylene bond in $\mathrm{B}-\mathrm{CH}_{2-}$, and the peaks at $5.88-6.19 \mathrm{ppm}$ (VI) are assigned to $-\mathrm{CH}=\mathrm{CH}_{2}$. Generally, the resulting polymer product was a mixture of $\alpha$-adduct and $\beta$-adduct, and according to ${ }^{1} \mathrm{H}$ NMR spectroscopy, the ratio of the $\alpha$-adduct over the $\beta$-adduct was 5:3, irrespective of the monomer type.

${ }^{11} \mathrm{~B}$ NMR (Figure 2d) confirmed the formation of B-N bonds by peak resonances with chemical shifts in -7-3 ppm range (M), confirming the dehydrogenation between $\mathrm{N}-\mathrm{H}$ and $\mathrm{B}-\mathrm{H}$. The peaks at $50 \mathrm{ppm}\left(\mathrm{D}^{1}\right)$ and $61 \mathrm{ppm}\left(\mathrm{D}^{2}\right)$ are assigned to $\mathrm{B}-\mathrm{CH}\left(\mathrm{CH}_{3}\right)$ - and $\mathrm{B}-\mathrm{CH}_{2}-\mathrm{CH}_{2}$. It could be concluded that the BSZ12 monomer was a mixture of $\beta$-adduct, $\alpha$-adduct, and products from dehydrogenation.

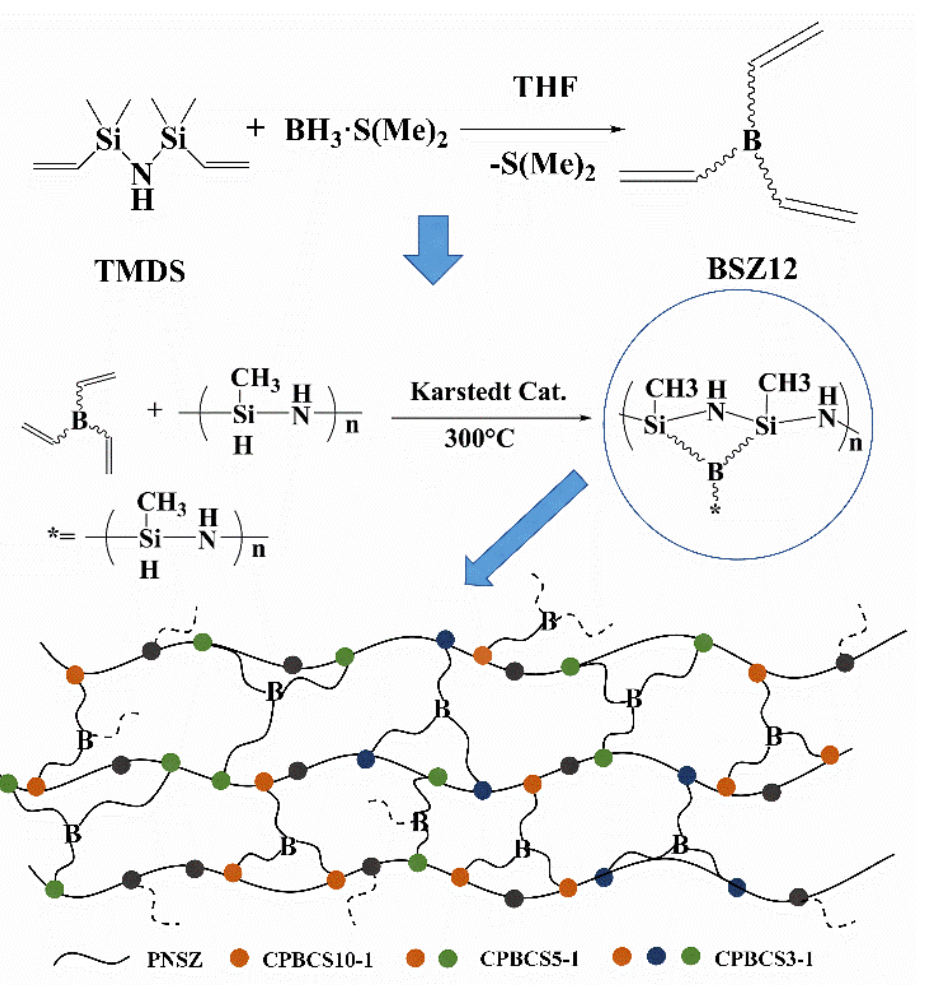

Figure 1. Synthetic route of boron hybrid polysilazane solid with cross-linking network (CPBCS) structure. 
(a)

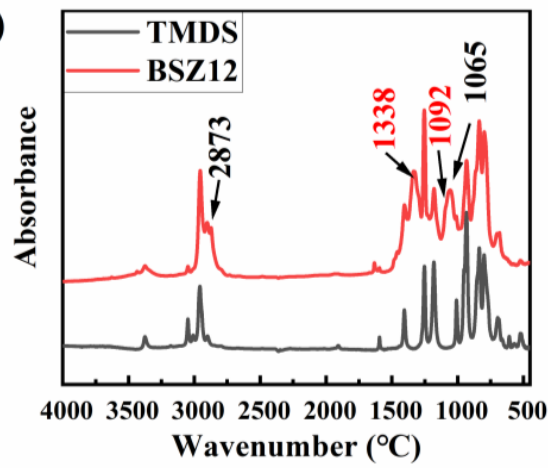

(c)

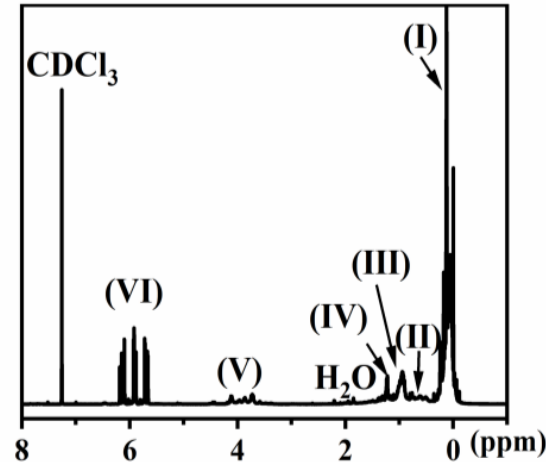

(b)

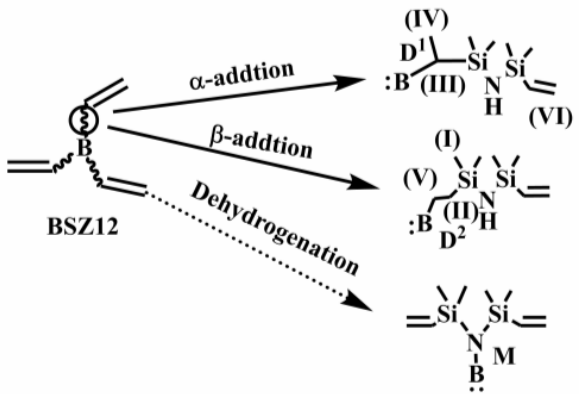

(d)

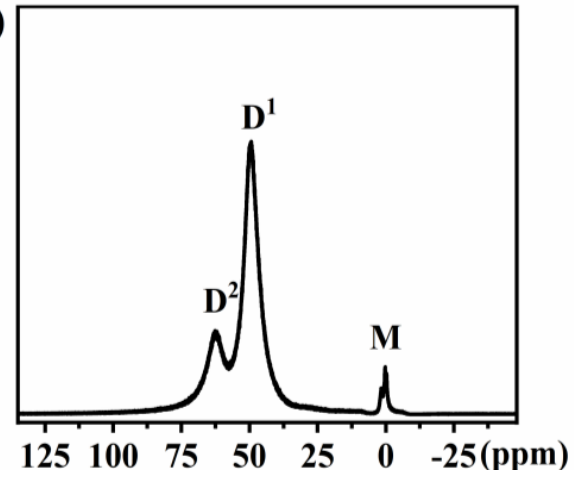

Figure 2. (a) Fourier transform infrared (FTIR) spectra of 1,1,3,3-tetramethyl-1,3-divinyldisilazane (TMDS) and BSZ12 monomers; (b) Structural composition of BSZ12 monomers; (c) ${ }^{1} \mathrm{H}$ NMR spectrum, and (d) ${ }^{11} \mathrm{~B}$ NMR spectrum of BSZ12 monomers.

\subsection{Synthesis of Crosslinked CPBCSs}

Karstedt Catalyst Solution was used to catalyze the crosslinking reaction between BSZ12 and PNSZ due to its high catalytic activity, wide applicability, lack of by-products, and contribution to the thermal stability/flame retardancy of polymer materials $[39,40]$. The molar ratios of $\mathrm{Si}-\mathrm{H}: \mathrm{C}=\mathrm{C}$ were 10:1, 5:1, and 3:1, and the samples were marked as CPBCS10-1, CPBCS5-1, and CPBCS3-1, respectively [15,41]. The Pt $(0)$ concentration was fixed at $412 \mathrm{ppm}$ to prevent catalyst poisoning by nitrogen atoms. Elemental analysis (Table 2) of the crosslinked products showed that the C and B content in the sample increased with increasing BSZ12. The boron content could be easily tuned by changing the ratios of PNSZ and BSZ12, and $1.37 \mathrm{wt} \% \mathrm{~B}$ content was achieved when $\mathrm{Si}-\mathrm{H}: \mathrm{C}=\mathrm{C}$ was 3-1. All the samples showed a high oxygen content around $20 \mathrm{wt} \%$, and the oxygen was not supposed to be present in the samples, since hydrosilylation reaction does not involve oxygen [42]. When we looked into the hydrosilylation catalyzed by $\mathrm{Pt}(0)$, we found that oxygen acts as a promoter and is involved in the formation of the intermediates [43]. The oxygen might be trapped in the materials, and at high temperatures, it could lead to the oxidation of $\mathrm{Si}-\mathrm{H}$ and exist as $\mathrm{Si}-\mathrm{O}-\mathrm{Si}$ in the final resin system. The oxygen content could not be quantitatively controlled, and further structure changes at $300{ }^{\circ} \mathrm{C}$ lead to variability in nitrogen and oxygen content.

The curing process of CPBCS was monitored by FTIR, as shown in Figure 3a. The intensity of the Si-H peak at $2145 \mathrm{~cm}^{-1}$ and the $\mathrm{C}=\mathrm{C}$ peak at $3058 \mathrm{~cm}^{-1}$ decreased gradually as the curing temperature increased. The progress of the crosslinking reaction by hydrosilylation and dehydrogenation was analyzed by observing the corresponding peak intensity change with increasing temperature. The sharp and single peak at $1260 \mathrm{~cm}^{-1}$ $\left(\mathrm{Si}-\mathrm{CH}_{3}\right)$ was used as an internal standard since it did not participate in the crosslinking process. The intensity ratio $R$ was calculated according to the following equation:

$$
R=h_{x} / h\left(\mathrm{Si}_{-}-\mathrm{CH}_{3}\right)
$$


where $h_{x}$ is the peak height of the changing bond and $h\left(\mathrm{Si}-\mathrm{CH}_{3}\right)$ is the height of the $\mathrm{Si}-\mathrm{CH}_{3}$ peak $\left(1260 \mathrm{~cm}^{-1}\right)$. The height of the Si-H and Si-O-Si peaks are $2138 \mathrm{~cm}^{-1}$ and $1035 \mathrm{~cm}^{-1}$.

Table 2. Polymer element content of crosslinked polymer CPBCS solids.

\begin{tabular}{cccc}
\hline Samples & CPBCS10-1 & CPBCS5-1 & CPBCS3-1 \\
\hline Si & $44.30 \%$ & $35.40 \%$ & $33.05 \%$ \\
C & $24.50 \%$ & $30.10 \%$ & $32.90 \%$ \\
$\mathrm{O}$ & $20.22 \%$ & $19.80 \%$ & $20.23 \%$ \\
$\mathrm{H}$ & $7.55 \%$ & $8.35 \%$ & $8.65 \%$ \\
$\mathrm{~N}$ & $2.80 \%$ & $5.33 \%$ & $3.80 \%$ \\
$\mathrm{~B}$ & $0.63 \%$ & $1.02 \%$ & $1.37 \%$ \\
\hline
\end{tabular}

(a)

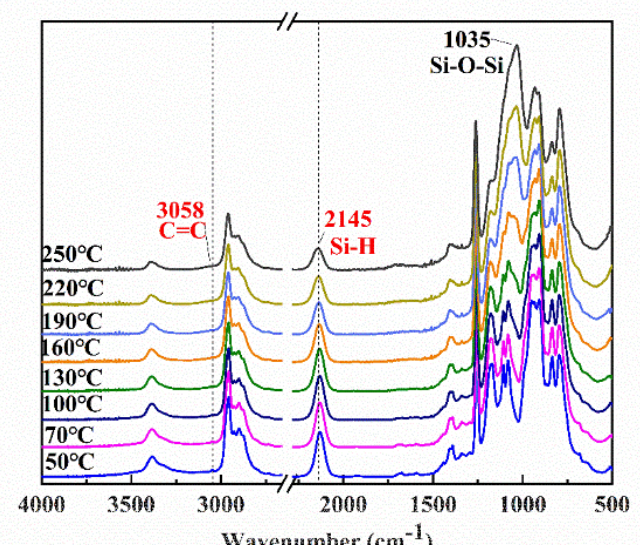

(b)

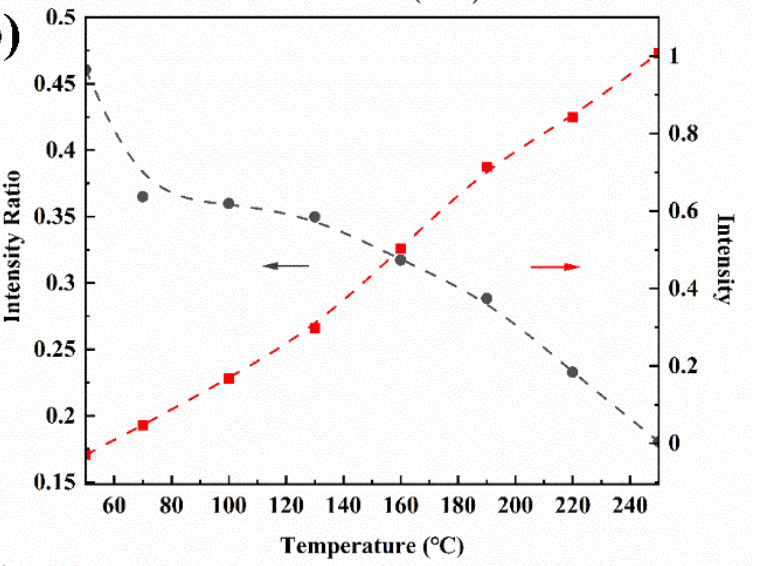

(c)

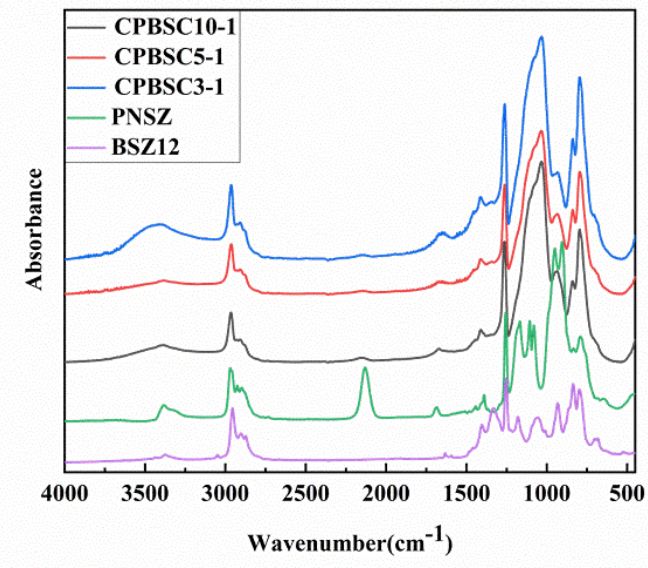

Figure 3. (a) FTIR spectra of CPBCS cured at different temperature for 2 h; (b) Peak intensity ratio of 2138 over $1260 \mathrm{~cm}^{-1}$ (gray), and 1035 over $1260 \mathrm{~cm}^{-1}$ (red) as a function of curing temperature; (c) FTIR spectra of CPBCS solids, BSZ12 and PNSZ were used to monitor the reaction. 
Si-H intensity decreased with temperature due to hydrosilylation consumption. (Figure $3 \mathrm{~b})$ The appearance of Si-O-Si $\left(1035 \mathrm{~cm}^{-1}\right)$ was due to the oxygen participation in the hydrosilation reaction, and the intensity increased with temperature. The formation of Si-O-Si also consumed part of the Si-H bonds. Figure $3 \mathrm{c}$ shows the FTIR spectra of fully crosslinked CPBCS samples after heat treatment at $300{ }^{\circ} \mathrm{C}$ for $2 \mathrm{~h}$. The disappeared Si-H bond $\left(2145 \mathrm{~cm}^{-1}\right)$ indicated that dehydrogenation between $\mathrm{Si}-\mathrm{H}$ and $\mathrm{Si}-\mathrm{H}$ or Si-H and N-H occurred, leading to higher crosslinking density.

\subsection{Optical Properties and Surface Characteristics of CPBCSs}

Figure 4 shows UV-Vis spectra and digital images of crosslinked CPBCS samples. The CPBCSs turned from light yellow to orange with increasing boron content, and the transmittance showed a bathochromic shift with increasing boron content. All the samples showed $\approx 0 \%$ transmittance below $360 \mathrm{~nm}$ because of the absorption of Pt from Karstedt Catalyst [44].

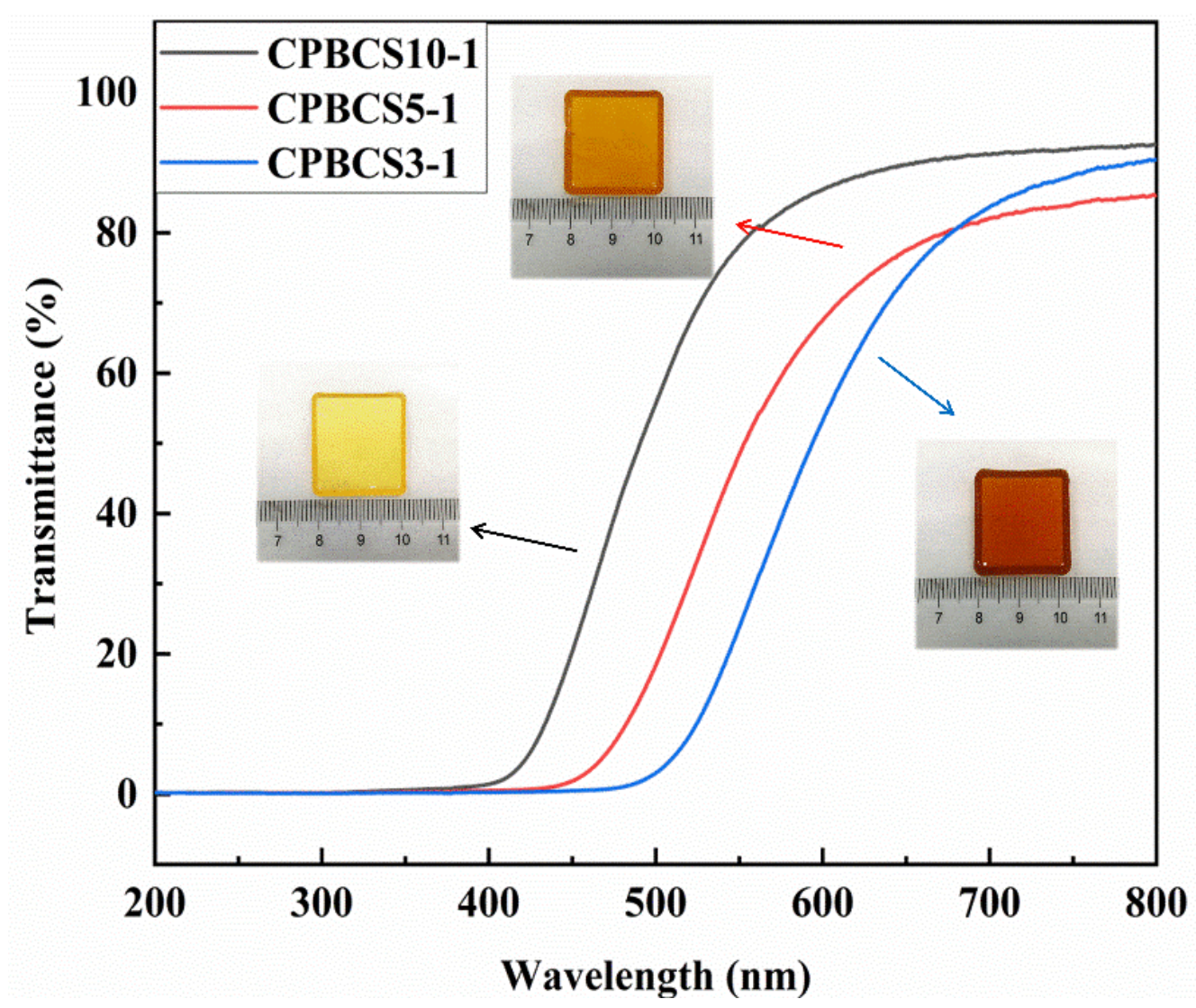

Figure 4. Digital images and UV-Vis transmission spectra of cross-linked CPBCS10-1, CPBCS5-1, and CPBCS3-1 polymers solids.

Figure 5 shows the typical topological images of the crosslinked CPBCSs. The morphologies revealed that CPBCSs have a smooth, crack-free surface $\left(10 \times 10 \mu \mathrm{m}^{2}\right)$. The mean square roughness $(\mathrm{Rq})$ values of CPBCS3-1, CPBCS5-1, and CPBCS10-1 were $0.324 \mathrm{~nm}$, $0.288 \mathrm{~nm}$, and $0.325 \mathrm{~nm}$, respectively. The results provided evidence that the organic and inorganic constituents of the hybrid polymer are distributed uniformly in the solids without any phase separation. 

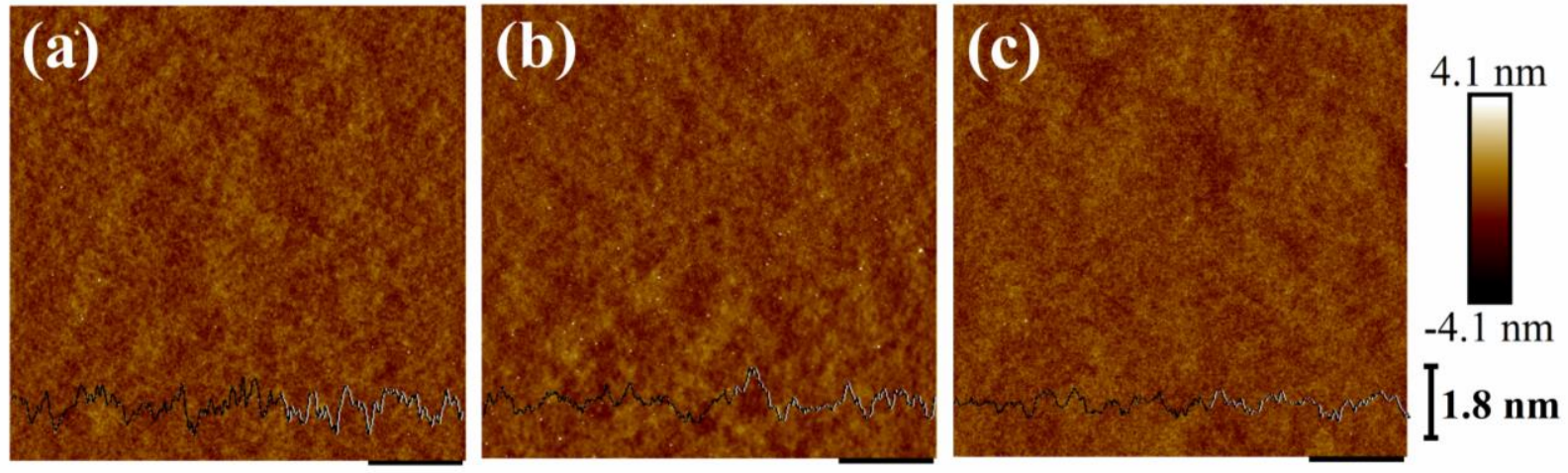

Height Sensor $2.0 \mathrm{um}$ Height Sensor $2.0 \mathrm{um}$ Height Sensor $2.0 \mathrm{um}$

Figure 5. AFM height images and section analyses of the free (air) surface of crosslinking network (a) CPBCS3-1, (b) CPBCS51, and (c) CPBCS10-1 solids (upper data).

Static contact angles of water were measured, and the results are presented in Figure 6. The contact angles were determined to be $103.65^{\circ}$ (CPBPS10-1), $106.43^{\circ}$ (CPBCS5-1), and $110.74^{\circ}$ (CPBCS3-1), which are comparable to that of extremely crosslinked silicone materials $\left(109^{\circ}\right)$ [45]. The hydrophobic surface is attributed to the formation of close-packed methyl groups at the surface resulting from the crosslinking of hybrid polymers with their chemical homogeneity as well as lower topographic roughness [45].
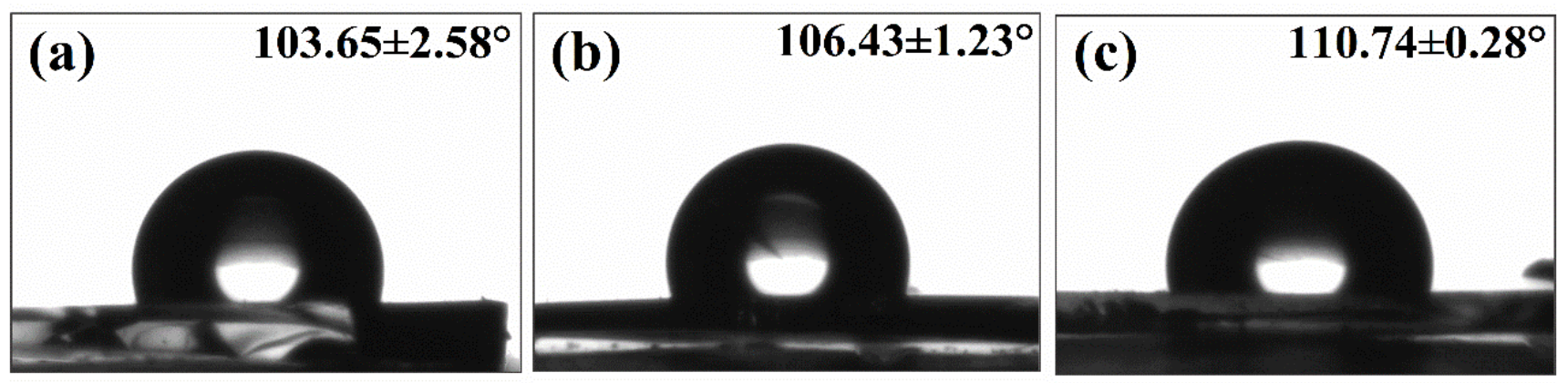

Figure 6. Static contact angles of water of CPBCS3-1, CPBCS5-1, and CPBCS10-1 polymers solids.

\subsection{Thermal Stability of $C P B C S s$}

Figure 7a shows the TG and 1st derivative of TG curves (dTG) in the argon atmosphere. Continuous mass loss was observed from $150{ }^{\circ} \mathrm{C}$, and the mass loss before $400{ }^{\circ} \mathrm{C}$ was mainly attributed to the loss of low molecular weight dimers. The weight loss around $400-600{ }^{\circ} \mathrm{C}$ is mainly due to the cleavage of $\mathrm{Si}-\mathrm{CH}_{3}$ bonds and $\mathrm{Si}-\mathrm{H}$ bonds, and the weight loss in $600-800{ }^{\circ} \mathrm{C}$ is mainly due to the cleavage of the $\mathrm{C}-\mathrm{C}$ framework in the form of methane and carbon dioxide gas [46]. The char yields at $1000{ }^{\circ} \mathrm{C}$ in argon were $75.38 \mathrm{wt} \%$, $72.05 \mathrm{wt} \%$, and $71.04 \mathrm{wt} \%$ for CPBCS10-1, CPBCS5-1, and CPBCS3-1, respectively. The char yields at $1000{ }^{\circ} \mathrm{C}$ in air were higher than those in argon, which is due to weight gain from oxidation. The high char yields indicated that CPBSC polymers could be used as preceramic polymers of $\mathrm{SiBCN}(\mathrm{O})$ [47].

Figure $7 \mathrm{~b}$ shows the char yields at $1000{ }^{\circ} \mathrm{C}$ in air were $79.9 \mathrm{wt} \%, 79.1 \mathrm{wt} \%$, and $77.4 \mathrm{wt} \%$ for CPBCS3-1, CPBCS5-1, and CPBCS10-1, respectively. BC units went through a similar oxidation behavior as $\mathrm{BN}(\mathrm{C})$, producing $\mathrm{B}_{2} \mathrm{O}_{3}$ phase. The $\mathrm{B}_{2} \mathrm{O}_{3}$ turned into liquid at high temperatures, which in turn prevents the oxidation of the inner materials by forming a protective layer [48]. $\mathrm{B}_{2} \mathrm{O}_{3}$ may react with glassy $\mathrm{SiO}_{2}$ to form stable borosilicate or $\mathrm{SiO}_{2}-\mathrm{B}_{2} \mathrm{O}_{3}$ binary melt, and the borosilicate glass can withstand up to $1600{ }^{\circ} \mathrm{C}$. The dense borosilicate glass layer inhibits further oxidation $[49,50]$. Therefore, the char yield increased with boron content. 

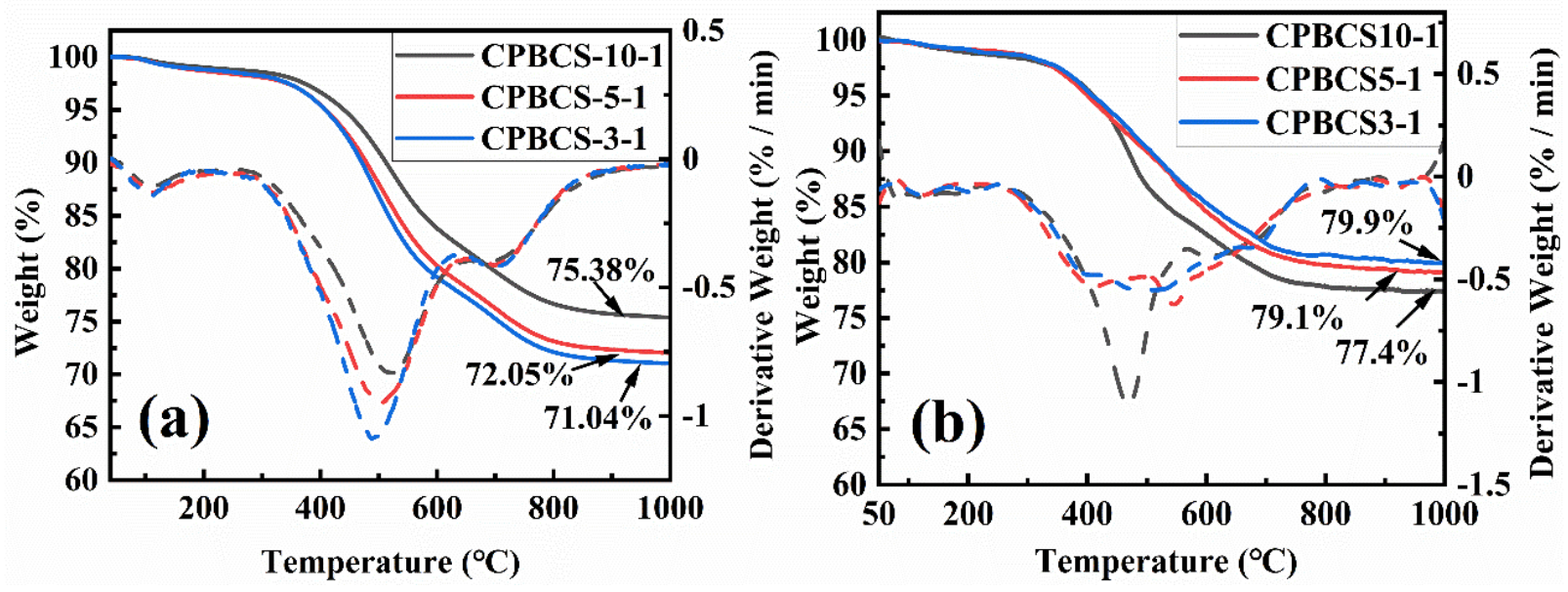

Figure 7. TG-dTG (derivative of TG curves) curves of CPBCSs: CPBCS3-1, CPBCS5-1, and CPBCS10-1 in argon (a) and in air (b).

\subsection{Flammability of $C P B C S$ s}

The flammability can be determined by the rate at which heat is released during burning. HRR vs. pyrolysis temperature plots of CPBCSs are shown in Figure 8, and the results are summarized in Table 3. The HRR profiles of CPBCSs shows multiple peaks. The first (the smallest) peak at $100-150^{\circ} \mathrm{C}$ is related to the initial decomposition of the small molecules. The main peaks at $300-570{ }^{\circ} \mathrm{C}$ were due to the decomposition of Si-C and C-C, which is in agreement with the STA conducted in argon (Figure 7a).

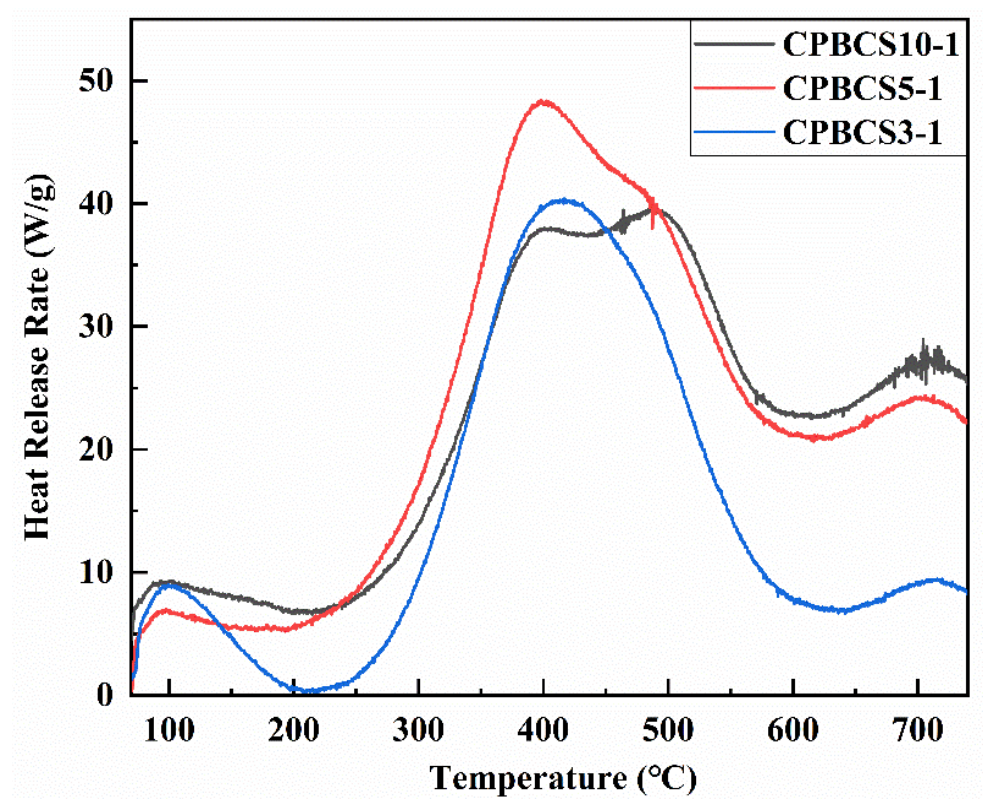

Figure 8. Heat release rate versus temperature in pyrolysis combustion flow calorimetry (PCFC) tests. 
Table 3. Data obtained from PCFC tests.

\begin{tabular}{|c|c|c|c|c|c|c|c|c|}
\hline Sample & $\begin{array}{c}\mathrm{pHRR}_{1} \\
(\mathrm{~W} / \mathrm{g})\end{array}$ & $\begin{array}{l}\mathrm{Tp}_{1} \\
\left({ }^{\circ} \mathrm{C}\right)\end{array}$ & $\begin{array}{c}\mathrm{pHRR}_{2} \\
(\mathrm{~W} / \mathrm{g})\end{array}$ & $\begin{array}{l}\mathrm{Tp}_{2} \\
\left({ }^{\circ} \mathrm{C}\right)\end{array}$ & $\begin{array}{c}\mathrm{pHRR}_{3} \\
(\mathrm{~W} / \mathrm{g})\end{array}$ & $\begin{array}{l}\mathrm{Tp}_{3} \\
\left({ }^{\circ} \mathrm{C}\right)\end{array}$ & $\begin{array}{c}\text { sumHRC } \\
(\mathrm{J} / \mathrm{g} \mathrm{K})\end{array}$ & $\begin{array}{c}\text { THR } \\
(\mathrm{kJ} / \mathrm{g})\end{array}$ \\
\hline CPBCS3-1 & 8.9 & 45.5 & 40.3 & 356.5 & - & - & 40 & 7.5 \\
\hline CPBCS5-1 & 6.9 & 46.0 & 48.3 & 342.1 & 41.1 & 436.0 & 43 & 9 \\
\hline CPBCS10-1 & 9.1 & 45.5 & 37.9 & 344.0 & 39.5 & 457.5 & 43 & 6.2 \\
\hline
\end{tabular}

The THR of CPBCSs is below $10 \mathrm{~kJ} / \mathrm{g}$, which is similar to that of flame-retardant polyimide (PI, sumHRC $38 \mathrm{~J} / \mathrm{g}$ K, THR $6.7 \mathrm{~J} / \mathrm{g} \mathrm{K}$ ) [51]. Compared with flame-retardant polyurethanes containing boron additives, CPBCSs have lower pHRR and sumHRC combustion peaks and higher peak thermal decomposition temperature [52].

The thermally stable B-N bond in the structure makes CPBCSs more stable. During the decomposition process, thermally stable bonds such as $\mathrm{B}-\mathrm{O}-\mathrm{C}$ are formed and further carbonized to form inorganic $\mathrm{B}_{2} \mathrm{O}_{3}$ or carbon, thus increasing the char yield and decreasing the heat release [50].

\subsection{Mechanical Properties of CPBCSs}

The mechanical properties were quantitatively assessed using nanoindentation. Figure 9 shows the load-displacement curve of CPBCSs. When the load reached $5 \mathrm{mN}$, the displacements of CPBCS10-1, CPBCS5-1, and CPBCS3-1 were $1155 \mathrm{~nm}, 1362 \mathrm{~nm}$, and $1785 \mathrm{~nm}$, respectively. After holding for $5 \mathrm{~s}$ under a constant force of $5 \mathrm{mN}$, the displacement of the three samples increased to $1201 \mathrm{~nm}, 1412 \mathrm{~nm}$, and $1913 \mathrm{~nm}$, respectively. The low indentation depth increases during the holding period indicated that all the CPBCS are hard and resistant to shape change. The elasticity decreased with increasing boron content, which is mainly attributed to the presence of free space between PNSZ chains for deformation, absorbing more energy. The reduced modulus and hardness of the crosslinked polymers are presented in Table 4 . CPBCS3-1 showed the lowest reduced modulus and hardness, while CPBCS10-1 showed the highest reduced modulus and hardness.

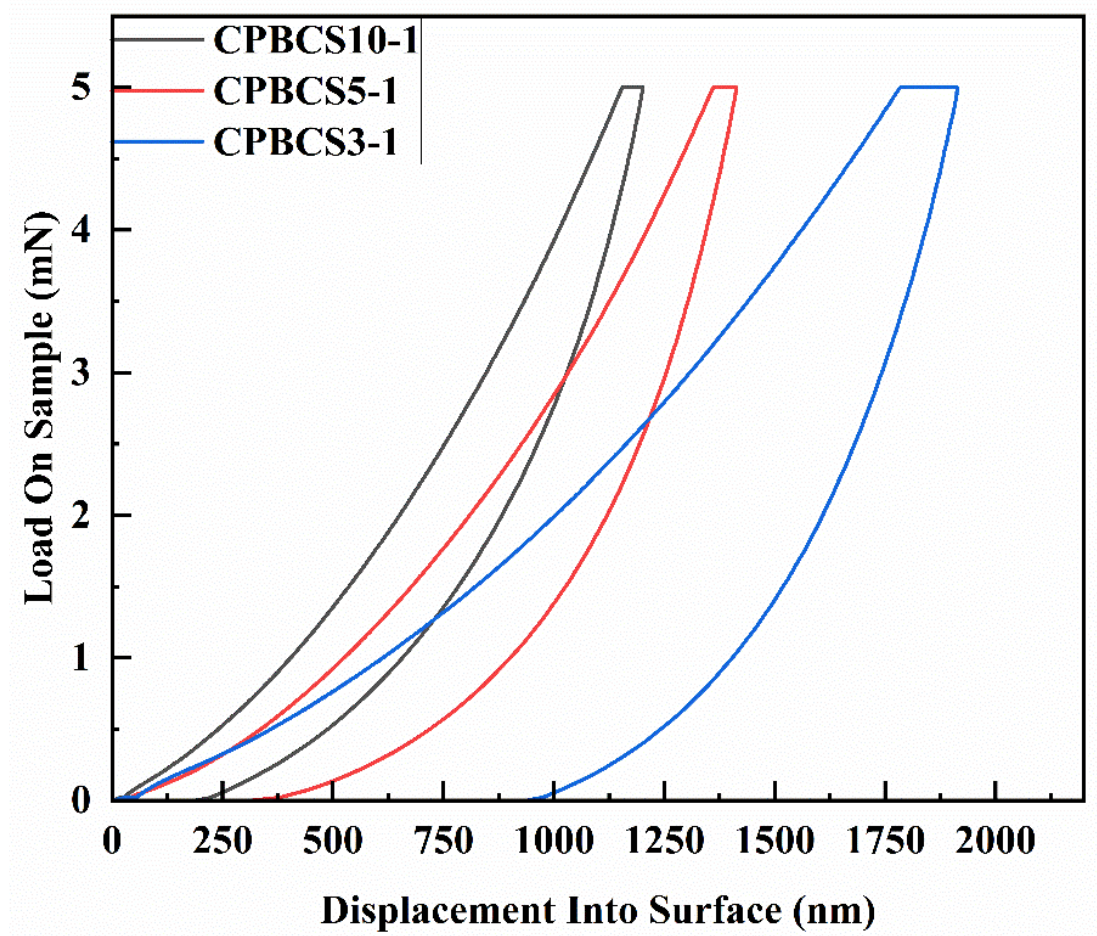

Figure 9. Nanoindentation curves of crosslinked CPBCSs. 
Table 4. Hardness and modulus of CPBCSs.

\begin{tabular}{cccc}
\hline & CPBCS10-1 & CPBCS5-1 & CPBCS3-1 \\
\hline Reduced Modulus (GPa) & $2.32 \pm 0.08$ & $1.93 \pm 0.09$ & $1.40 \pm 0.10$ \\
Hardness (GPa) & $0.30 \pm 0.02$ & $0.18 \pm 0.01$ & $0.09 \pm 0.01$ \\
\hline
\end{tabular}

\subsection{An Insight into CPBCSs' Structure}

When BSZ12 and PNSZ undergo hydrosilylation reaction, the Si-H from PNSZ could not be completely consumed, since excessive Si-H groups were employed in the synthesis process. The use of BSZ12 also introduced space between crosslinking points. Further heat treatment at $300{ }^{\circ} \mathrm{C}$ for $2 \mathrm{~h}$ led to degeneration reactions between $\mathrm{Si}-\mathrm{H}$ and $\mathrm{Si}-\mathrm{H}$, and Si-H and N-H. However, in CPBCS 3-1, the crosslinking density is high, and the Si-H and N-H groups on the chains cannot react easily due to steric hindrance. A similar situation exists in CPBCS5-1. However, when it comes to CPBCS10-1, the PNSZ chains between crosslinking points are long enough to entangle with each other and contribute to dehydrogenation reaction at $300{ }^{\circ} \mathrm{C}$. The additional dehydrogenation reaction in CPBCS10-1 contributes to a higher crosslinking density than that of CPBCS5-1 and CPBCS3-1, showing better mechanical properties. At the same time, with the increase of BSZ12, the boron and B-C structure content in CPBCS also increase, which contributes to the high-temperature oxidation stability of the material and provides more reliable flame retardant and fire resistance.

\section{Conclusions}

Novel polyborosilazanes were successfully fabricated through a two-component route via hydrodilylation. The boron content and polymeric structure could be readily tuned through changing the $\mathrm{Si}-\mathrm{H} / \mathrm{C}=\mathrm{C}$ ratios. The solventless preparation process relieves the pressure on the environment and reduces the waste of resources. The increase of boron content and $\mathrm{B}-\mathrm{C}$ structure in $\mathrm{CPBCSs}$ can form $\mathrm{SiO}_{2}-\mathrm{B}_{2} \mathrm{O}_{3}$ binary melt and borosilicate glass, forming a dense oxide layer to reduce its heat release, which hinders heat transfer to the underlying polymer. СРBCSs showed good thermal stability and thermal oxidation performance, and they also showed good flame retardancy with an HRR lower than $50 \mathrm{~W} / \mathrm{g}$. The as-prepared polyboronsilazanes could be potentially used as preceramic polymers to produce $\mathrm{SiBCN}(\mathrm{O})$ ceramic components for high-temperature applications and flame retardant coatings to protect materials against fire or oxidation.

Author Contributions: Conceptualization, B.W. and Y.S.; Methodology, Y.S.; Validation, B.W.; Formal Analysis, B.W., X.S. and T.L.; Investigation, B.W.; Resources, K.C., J.X.; Data Curation, B.W. and L.Y.; Writing-Original Draft Preparation, B.W.; Writing-Review and Editing, X.H., Y.S. and M.L.; Supervision, L.H. and Y.S.; Project Administration, Q.H., L.J.; Funding Acquisition, Q.H. and L.J. All authors have read and agreed to the published version of the manuscript.

Funding: This study was financially supported by the National Natural Science Foundation of China, grant number 51963001; the Dean Project of Guangxi Key Laboratory of Petrochemical Resource Processing and Process Intensification Technology, Guangxi University, grant number 2018Z002; and 3315 Innovation Teams in Ningbo City, grant number 2018A-03-A.

Institutional Review Board Statement: Not applicable.

Informed Consent Statement: Not applicable.

Data Availability Statement: The data presented in this study are available on request from the corresponding author.

Acknowledgments: Yujie Song acknowledges the financial support from the Chinese Academy of Sciences. Ke Chen acknowledges the support from the International Postdoctoral Exchange Fellowship Program of China.

Conflicts of Interest: The authors declare no conflict of interest. 


\section{References}

1. Macan, J.; Brnardic, I.; Orlic, S.; Ivankovic, H.; Ivankovic, M. Thermal degradation of epoxy-silica organic-inorganic hybrid materials. Polym. Degrad. Stab. 2006, 91, 122-127. [CrossRef]

2. Kanamori, K.; Aizawa, M.; Nakanishi, K.; Hanada, T. Elastic organic-inorganic hybrid aerogels and xerogels. J. Sol-Gel Sci. Technol. 2008, 48, 172-181. [CrossRef]

3. Fu, R.Q.; Woo, J.J.; Seo, S.J.; Lee, J.S.; Moon, S.H. Covalent organic/inorganic hybrid proton-conductive membrane with semi-interpenetrating polymer network: Preparation and characterizations. J. Power Sources 2008, 179, 458-466. [CrossRef]

4. Pandey, S.; Mishra, S.B. Sol-gel derived organic-inorganic hybrid materials: Synthesis, characterizations and applications. J. Sol-Gel Sci. Technol. 2011, 59, 73-94. [CrossRef]

5. Wu, Y.H.; Wu, C.M.; Xu, T.W.; Fu, Y.X. Novel anion-exchange organic-inorganic hybrid membranes prepared through sol-gel reaction of multi-alkoxy precursors. J. Membr. Sci. 2009, 329, 236-245. [CrossRef]

6. Hu, H.; Wang, L.; Wang, L.; Li, L.; Feng, S. Imine-functionalized polysiloxanes for supramolecular elastomers with tunable mechanical properties. Polym. Chem. 2020, 11, 7721-7728. [CrossRef]

7. Ruiz-Hitzky, E.; Aranda, P.; Darder, M.; Ogawa, M. Hybrid and biohybrid silicate based materials: Molecular vs. block-assembling bottom-up processes. Chem. Soc. Rev. 2011, 40, 801-828. [CrossRef] [PubMed]

8. Kundu, C.K.; Li, Z.W.; Song, L.; Hu, Y. An overview of fire retardant treatments for synthetic textiles: From traditional approaches to recent applications. Eur. Polym. J. 2020, 137. [CrossRef]

9. Mosurkal, R.; Kirby, R.; Muller, W.S.; Soares, J.W.; Kumar, J. Simple green synthesis of polyborosiloxanes as environmentally-safe, non-halogenated flame retardant polymers. Green Chem. 2011, 13, 659-665. [CrossRef]

10. Mosurkal, R.; Samuelson, L.A.; Parmar, V.S.; Kumar, J.; Watterson, A.C. Biocatalytic synthesis of organosiloxane copolyimide. Macromolecules 2007, 40, 7742-7744. [CrossRef]

11. Mosurkal, R.; Samuelson, L.A.; Tewari, A.; Watterson, A.C.; Parmar, V.S.; Kumar, J. Crosslinking of Polydimethyl Siloxane Copolymers with Aromatic Dianhydrides: The Study of Thermal and Flame Retardant Properties. J. Macromol. Sci. Part A Pure Appl. Chem. 2009, 46, 1228-1232. [CrossRef]

12. Wesolek, D.; Gasiorowski, R.; Rojewski, S.; Walentowska, J.; Wojcik, R. New Flexible Flame Retardant Coatings Based on Siloxane Resin and Ethylene-Vinyl Chloride Copolymer. Polymers 2016, 8, 419. [CrossRef] [PubMed]

13. Xie, W.; Guo, S.; Liu, Y.; Chen, R.; Wang, Q. Organic-inorganic hybrid strategy based on ternary copolymerization to prepare flame retardant poly(methyl methacrylate) with high performance. Compos. Part B Eng. 2020, 203, 108437. [CrossRef]

14. Bouquey, M.; Brochon, C.; Bruzaud, S.; Mingotaud, A.F.; Schappacher, M.; Soum, A. Ring-opening polymerization of nitrogencontaining cyclic organosilicon monomers. J. Organomet. Chem. 1996, 521, 21-27. [CrossRef]

15. Brook, M.A. Silicon in Organic, Organometallic, and Polymer Chemistry; John Wiley \& Sons: New York, NY, USA, $2000 ;$ Volume 123.

16. Olejarka, J.; Lacz, A.; Olejniczak, Z.; Hasik, M. Non-porous and porous materials prepared by cross-linking of polyhydromethylsiloxane with silazane compounds. Eur. Polym. J. 2018, 99, 150-164. [CrossRef]

17. Sun, J.T.; Huang, Y.D.; Cao, H.L.; Gong, G.F. Effects of ambient-temperature curing agents on the thermal stability of poly(methylphenylsiloxane). Polym. Degrad. Stab. 2004, 85, 725-731. [CrossRef]

18. Kroke, E.; Li, Y.L.; Konetschny, C.; Lecomte, E.; Fasel, C.; Riedel, R. Silazane derived ceramics and related materials. Mater. Sci. Eng. R Rep. 2000, 26, 97-199. [CrossRef]

19. Zhang, J.D.; Teng, Y.D.; Li, X.R.; Wang, S.L. Progress in synthesis and application of silazane. Chin. J. Org. Chem. 2007, 27, 1358-1365. [CrossRef]

20. Krüger, C.R.; Rochow, E.G. Polyorganosilazanes. J. Polym. Sci. Part A Gen. Pap. 1964, 2, 3179-3189. [CrossRef]

21. Seyferth, D. Synthesis of Some Organosilicon Polymers and Their Pyrolytic Conversion to Ceramics. In Silicon-Based Polymer Science; American Chemical Society: Washington, DC, USA, 1989; Volume 224, pp. 565-591.

22. Ahmad, F.; Zulkurnain, E.S.B.; Ullah, S.; Al-Sehemi, A.G.; Raza, M.R. Improved fire resistance of boron nitride/epoxy intumescent coating upon minor addition of nano-alumina. Mater. Chem. Phys. 2020, 256. [CrossRef]

23. Arslan, F.; Dilsiz, N. Flame resistant properties of LDPE/PLA blends containing halogen-free flame retardant. J. Appl. Polym. Sci. 2020, 137. [CrossRef]

24. Donmez Cavdar, A.; Mengeloğlu, F.; Karakus, K. Effect of boric acid and borax on mechanical, fire and thermal properties of wood flour filled high density polyethylene composites. Measurement 2015, 60, 6-12. [CrossRef]

25. Feng, C.; Zhang, Y.; Liang, D.; Liu, S.; Chi, Z.; Xu, J. Influence of zinc borate on the flame retardancy and thermal stability of intumescent flame retardant polypropylene composites. J. Anal. Appl. Pyrolysis 2015, 115, 224-232. [CrossRef]

26. Green, J. Mechanisms for Flame Retardancy and Smoke suppression-A Review. J. Fire Sci. 2016, 14, 426-442. [CrossRef]

27. Riensch, N.A.; Deniz, A.; Kuhl, S.; Muller, L.; Adams, A.; Pich, A.; Helten, H. Borazine-based inorganic-organic hybrid cyclomatrix microspheres by silicon/boron exchange precipitation polycondensation. Polym. Chem. 2017, 8, 5264-5268. [CrossRef]

28. Abdalla, M.O.; Ludwick, A.; Mitchell, T. Boron-modified phenolic resins for high performance applications. Polymer 2003, 44, 7353-7359. [CrossRef]

29. Ma, C.; Ma, Z.; Gao, L.H.; Liu, Y.B.; Wu, T.T.; Wang, F.C.; Ishida, H. Ablation behavior of boron-modified phenolic resin irradiated by high-energy continuous-wave laser and its evolution of carbon structure. Mater. Des. 2019, 180, 107954. [CrossRef]

30. Wang, F.; Huang, Z.; Guo, Z. Bionic boron/silicon-modified phenolic resin system with multifunctional groups: Synthesis, thermal properties and ablation mechanism. Biosurf. Biotribol. 2018, 4, 85-93. [CrossRef] 
31. Yajima, S.; Hayashi, J.; Okamura, K. Pyrolysis of a Polyborodiphenylsiloxane. Nature 1977, 266, 521-522. [CrossRef]

32. Sundar, R.A.; Keller, T.M. Synthesis and characterization of linear boron-silicon-diacetylene copolymers. Macromolecules 1996, 29 , 3647-3650. [CrossRef]

33. Zhou, Q.; Feng, X.; Ni, L.Z.; Chen, J.D. Novel heat resistant methyl-tri(phenylethynyl)silane resin: Synthesis, characterization and thermal properties. J. Appl. Polym. Sci. 2006, 102, 2488-2492. [CrossRef]

34. Zhou, H.; Zhou, Q.; Zhou, Q.; Ni, L.Z.; Chen, Q. Highly heat resistant and thermo-oxidatively stable borosilane alkynyl hybrid polymers. RSC Adv. 2015, 5, 12161-12167. [CrossRef]

35. Zhang, Q.; Yang, Z.H.; Jia, D.C.; Chen, Q.Q.; Zhou, Y. Synthesis and structural evolution of dual-boron-source-modified polysilazane derived SiBCN ceramics. New J. Chem. 2016, 40, 7034-7042. [CrossRef]

36. Haberecht, J.; Krumeich, F.; Grutzmacher, H.; Nesper, R. High-yield molecular borazine precursors for Si-B-N-C ceramics. Chem. Mater. 2004, 16, 418-423. [CrossRef]

37. Oliver, W.C.; Pharr, G.M. An improved technique for determining hardness and elastic modulus using load and displacement sensing indentation experiments. J. Mater. Res. 2011, 7, 1564-1583. [CrossRef]

38. Viard, A.; Fonblanc, D.; Lopez-Ferber, D.; Schmidt, M.; Lale, A.; Durif, C.; Balestrat, M.; Rossignol, F.; Weinmann, M.; Riedel, R.; et al. Polymer Derived Si-B-C-N Ceramics: 30 Years of Research. Adv. Eng. Mater. 2018, 20. [CrossRef]

39. Liu, T.; Zeng, X.; Lai, X.; Li, H.; Wang, Y. Remarkable improvement of organic-to-inorganic conversion of silicone rubber at elevated temperature through platinum-nitrogen catalytic system. Polym. Degrad. Stab. 2020, 171, 109026. [CrossRef]

40. Maeda, K.; Motokura, K. Recent Advances on Heterogeneous Metal Catalysts for Hydrosilylation of Olefins. J. Jpn. Pet. Inst. 2020, 63, 1-9. [CrossRef]

41. Troegel, D.; Stohrer, J. Recent advances and actual challenges in late transition metal catalyzed hydrosilylation of olefins from an industrial point of view. Coord. Chem. Rev. 2011, 255, 1440-1459. [CrossRef]

42. Hofmann, R.J.; Vlatkovic, M.; Wiesbrock, F. Fifty Years of Hydrosilylation in Polymer Science: A Review of Current Trends of Low-Cost Transition-Metal and Metal-Free Catalysts, Non-Thermally Triggered Hydrosilylation Reactions, and Industrial Applications. Polymers 2017, 9, 534. [CrossRef]

43. Wong, M.Y.; Schneider, A.F.; Lu, G.H.; Chen, Y.; Brook, M.A. Autoxidation: Catalyst-free route to silicone rubbers by crosslinking Si-H functional groups. Green Chem. 2019, 21, 6483-6490. [CrossRef]

44. Zheng, P.; McCarthy, T.J. Rediscovering silicones: Molecularly smooth, low surface energy, unfilled, UV/vis-transparent, extremely cross-linked, thermally stable, hard, elastic PDMS. Langmuir 2010, 26, 18585-18590. [CrossRef] [PubMed]

45. Demirci, A.; Yamamoto, S.; Matsui, J.; Miyashita, T.; Mitsuishi, M. Facile synthesis of cyclosiloxane-based polymers for hybrid film formation. Polym. Chem. 2015, 6, 2695-2706. [CrossRef]

46. Yuan, Q.; Yao, B.; Huang, Z.R.; Huang, Q. Developing a liquid and curable two-component precursor system for fabrication of $\mathrm{SiC}(\mathrm{N})$-based composites. Ceram. Int. 2019, 45, 24007-24013. [CrossRef]

47. Tang, B.J.; Zhang, Y.; Hu, S.J.; Feng, B. A dense amorphous $\operatorname{SiBCN}(\mathrm{O})$ ceramic prepared by simultaneous pyrolysis of organics and inorganics. Ceram. Int. 2016, 42, 5238-5244. [CrossRef]

48. Guo, X.; Wang, D.; Guo, Z.; Zhang, Z.B.; Cui, M.Z.; Xu, C.H. SiBCN-precursor-derived gradient oxidation protective ceramic coating for C/C composites. Surf. Coat. Technol. 2018, 350, 101-109. [CrossRef]

49. Li, D.X.; Yang, Z.H.; Jia, D.C.; Duan, X.M.; Cai, D.L.; Wang, S.J.; Yuan, J.K.; Zhou, Y.; Yu, D.L.; Tian, Y.J. High-temperature oxidation resistance of dense amorphous boron-rich SiBCN monoliths. Corros. Sci. 2019, 157, 312-323. [CrossRef]

50. Morgan, A.B.; Jurs, J.L.; Tour, J.M. Synthesis, flame-retardancy testing, and preliminary mechanism studies of nonhalogenated aromatic boronic acids: A new class of condensed-phase polymer flame-retardant additives for acrylonitrile-butadiene-styrene and polycarbonate. J. Appl. Polym. Sci. 2000, 76, 1257-1268. [CrossRef]

51. Lyon, R.E.; Walters, R.N. Pyrolysis combustion flow calorimetry. J. Anal. Appl. Pyrolysis 2004, 71, 27-46. [CrossRef]

52. Benin, V.; Gardelle, B.; Morgan, A.B. Heat release of polyurethanes containing potential flame retardants based on boron and phosphorus chemistries. Polym. Degrad. Stab. 2014, 106, 108-121. [CrossRef] 